\title{
Micro-nondestructive detection of the moisture and ion of rice seeds during germination under salt stress
}

\author{
Hongwei Yang ${ }^{1,2,3,4}$, Jianwei $\mathrm{Ji}^{1^{*}}$, Cheng Wang ${ }^{2,3,4}$, Liying Zhang ${ }^{5}$, Xiaodong Wang ${ }^{2,3,4}$, \\ Ping Song ${ }^{1}$, Peng Song ${ }^{2,3,4}$ \\ (1. College of Information and Electrical Engineering, Shenyang Agricultural University, Shenyang 110866, China; \\ 2. National Research Center of Intelligent Equipment and Technology for Agriculture, Beijing 100097, China; \\ 3. Key Laboratory of Agri-Informatics, Ministry of Agriculture, Beijing 100097, China; \\ 4. Beijing Key Laboratory of Intelligent Equipment and Technology for Agriculture, Beijing 100097, China; \\ 5. Liaoning Rice Research Institute, Shenyang 110161, China)
}

\begin{abstract}
Salt stress is one of the major stress factors limiting rice productivity. Its damaging effects include water deficit due to osmotic stress, and ionic toxicity caused by ionic stress. It is very important to study the salt-tolerance mechanism of rice under salt stress, in order to improve the salt-tolerance capacity of rice and thereby increase the yield. In this experiment, the low field nuclear magnetic resonance (LF NMR) technique and the traditional dry-weight weighing method, the non-invasive micro-test technique (NMT) and the inductively coupled plasma emission spectrometry (ICP-AES) were applied to analyze the distribution of water and the flow of $\mathrm{K}^{+}$and $\mathrm{Na}^{+}$of rice seeds during germination under $\mathrm{NaCl}$ stress. The results suggested that for all different $\mathrm{NaCl}$ concentrations, as germination hours grew, the amplitude of NMR signals of the bound water that of the free water and the total amplitude all increased gradually. And the higher the $\mathrm{NaCl}$ concentration is, the weaker the increase trend is. In addition, the moisture content of the seeds and the total amplitude of NMR signals were positively correlated. The regression equation was $y=191.53 x+1463.6$, the correlation coefficient was $R=0.9823$, and the determination coefficient was $R^{2}=0.9650$. By this regression equation, the moisture content of each state of water during seed germination can be calculated. When without $\mathrm{NaCl}$ stress, the rice seeds absorbed $\mathrm{K}^{+}$in the germination process. However, when under $\mathrm{NaCl}$ stress at different concentrations, $\mathrm{K}^{+}$efflux was detected. The contents of $\mathrm{K}^{+}$and $\mathrm{K}^{+} / \mathrm{Na}^{+}$were lower than that under the control condition. The higher $\mathrm{NaCl}$ concentration is, the lower the $\mathrm{K}^{+}$and $\mathrm{K}^{+} / \mathrm{Na}^{+}$contents are. These results are in consistence with the $\mathrm{K}^{+}$and $\mathrm{Na}^{+}$contents detected by the inductively coupled technique. These empirical data offer a reference for the study of rice-seeds' response mechanism under salt stress during germination and the screening of germplasm resources, and also put forward a new method of biopsy micro-nondestructive test for plants under stress.
\end{abstract}

Keywords: nuclear magnetic resonance (NMR), non-invasive micro-test (NMT), $\mathrm{NaCl}$ stress, seed germination, moisture, dynamic ion flow

DOI: $10.25165 /$ j.ijabe.20191202.4245

Citation: Yang H W, Ji J W, Wang C, Zhang L Y, Wang X D, Song P, et al. Micro-nondestructive detection of the moisture and ion of rice seeds during germination under salt stress. Int J Agric \& Biol Eng, 2019; 12(2): 103-110.

\section{Introduction}

Rice is the second most important food crop in the world and provides staple food for $50 \%$ of the world's population. The salinization of paddy soil has seriously affected the growth of rice and thereby constrains the increase of rice yield. According to

\section{Received date: $2018-03-20 \quad$ Accepted date: 2019-03-13}

Biographies: Hongwei Yang, PhD candidate, research interests: agricultural informationization and precision agriculture, Email: yhwsyau@163.com; Cheng Wang, PhD, Researcher, research interests: intelligent equipment and biological instruments for agriculture, Email: wangc@nercita.org.cn; Liying Zhang, Master, Research Assistant, research interests: breeding of rice varieties, Email: cytaa3@163.com; Xiaodong Wang, PhD, Research Assistant, research interests: nondestructive testing technology for plant physiological signals, Email: wangxd@nercita.org.cn; Ping Song, PhD, research interests: precision agriculture. Email: songping_1010@163.com; Peng Song, PhD, Research Assistant, research interests: agricultural information acquisition technologies and equipment, Email: songp@nercita.org.cn.

*Corresponding author: Jianwei $\mathbf{J i}, \mathrm{PhD}$, Professor, research interests: control and intelligent detection of biological environment in the agricultural context. College of Information and Electrical Engineering, Shenyang Agricultural University, Shenyang 110866, China. Tel: +86-13019346595, Email: jianweiji7879@163.com. statistics, more than $30 \%$ of paddy field around the globe suffers from varying degrees of salinization. $\mathrm{NaCl}$ is one of the main elements of soil salinity ${ }^{[1,2]}$. Therefore, in order to enhance the selection of salt-tolerant rice germplasm resources, the evaluation of salt tolerance, and the cultivation of salt-tolerant rice varieties, it is very important to fully understand the physiological response mechanism of rice under saline-alkali stress. The germination period is the key for the survival of plants under salt stress ${ }^{[3-5]}$. Up to date, domestic and oversea studies on the effect of salt stress on seed germination, typically has focused on the relative moisture content, germination rate, ion content and other parameters on the early stage ${ }^{[6-9]}$. These methods involved invasive testing, which can lead to colossal waste of germplasm resources.

Nuclear magnetic resonance (NMR) is a non-destructive, non-invasive detecting technique, and can reveal the variation pattern of moisture in samples on the microscopic level. Song et al. ${ }^{[10,11]}$ used low-field NMR technique to predict the moisture phase state and distribution characteristics of rice seeds through detecting the vigor and soaking process. Yang et al. ${ }^{[12]}$ used magnetic resonance imaging and nuclear magnetic resonance relaxation spectrum to find the moisture transport rules of rice 
seeds during germination process under polyethylene glycol press. Duan et al. ${ }^{[13]}$ used low-field NMR to analyze the moisture transformation and transport rules during processing of paeoniae radix alba. Guo et al. ${ }^{[14]}$ used thermo-gravimetric NMR to analyze the characterization of moisture mobility and diffusion in fresh tobacco leaves during drying process. Non-invasive micro-test technique (NMT) is a real-time dynamic biopsy detection technology. It can reveal life activity by measuring the flow of ions and small molecules in and out of live material, regardless of its nature. It can obtain information on the power and direction of the spatial motion of ions and small molecules, without using markers or extracting samples. Compared with patch clamp technique, NMT has irreplaceable advantages both in terms of space and time, and is being applied to the fields of basic biology, medicine and agronomy ${ }^{[15-21]}$, However, the detection of the moisture and ion of rice seeds during germination under salt stress using NMR and NMT technique has rarely been reported.

In this research, the rice seeds during germination were chosen as study object, the transverse relaxation time $\left(T_{2}\right)$ inversion spectrum of NMR and the scanning ion-selective electrode technique (SIET) in the non-invasive micro-test technique were utilized to analyze the changes of water absorption and the dynamic flowing mechanism of $\mathrm{K}^{+}$and $\mathrm{Na}^{+}$under $\mathrm{NaCl}$ stress of different concentrations, and thereby seek to reveal the variation pattern of water molecules and mineral ions absorbed by rice seeds during germination under salt stress. The empirical data will provide some reference for the study of rice-seeds' response mechanism during germination under salt stress, and for the development of the biopsy micro-nondestructive test technique in the study of plants under stress and the screening of germplasm resources.

\section{Materials and methods}

\subsection{Equipment and apparatus}

MINIMR-60 NMR machine (magnetic field strength: $0.5 \mathrm{~T}$; RF pulse frequency: $12 \mathrm{MHz}$; probe coil diameter: $15 \mathrm{~mm}$; magnet temperature: $32^{\circ} \mathrm{C}$, Shanghai Niumag Electronic Technology Co., Ltd.); microscopic dynamic ion-flow detection system for plants (National Engineering Research Center for Information Technology in Agriculture); inductively coupled plasma mass spectrometer ICP-MS (model: Agilent 7700x, Agilent Technologies); glass microelectrode (Xuyue (Beijing) Sci.\&Tech. Co., Ltd.); high-throughput tissue grinder: TissueLyser II (Shanghai Qiagen Biotech Co., Ltd.); HPG-280BX illumination incubator (temperature: $(27 \pm 1)^{\circ} \mathrm{C}$, Beijing Donglian Har Instrument Manufacture Co., Ltd); electric blower drying box: GZ-9023MBE (the Medical Equipment Factory of Shanghai Boxun Industrial Co., Ltd.); microbalance XS105DU (readability: 0.0001 g, max capacity: 120 g, Swiss Metteletoli Scientific Instrument Co., Ltd.); glass culture dish.

Chemical reagents: $\mathrm{K}^{+}$ion exchanger (Xuyue (Beijing) Sci.\&Tech. Co., Ltd.); $\mathrm{K}^{+}$filling liquid $(100 \mathrm{mM} \mathrm{KCl}) ; \mathrm{K}^{+}$test fluid $\left(0.1 \mathrm{mM} \mathrm{CaCl}_{2}, 0.1 \mathrm{mM} \mathrm{MgCl}_{2}, 0.1 \mathrm{mM} \mathrm{KCl}, 0.5 \mathrm{mM} \mathrm{NaCl}, 0.2\right.$ $\left.\mathrm{mM} \mathrm{Na} \mathrm{SO}_{4}\right) ; \mathrm{K}^{+}$correction fluid $(1 \mathrm{mM} \mathrm{KCl}, 0.1 \mathrm{mM} \mathrm{KCl})$; $\mathrm{NaClO}$; deionized water.

\subsection{Methods}

\subsubsection{Sample preparation and treatment}

This experiment was conducted from July 2017 to February 2018 in the micro-physiologic laboratory and seed quality testing laboratory of National Engineering Research Center for Information Technology in Agriculture. The rice seeds, Yanjing 48 (YG48) and Liaoxing 1 (LX1), were provided by Liaoning Rice
Research Institute. Year of production of the seeds was 2016. For each variety of rice seeds, 4200 full grains of similar appearance were selected, and divided into 210 groups, with 20 grains in each group. Among these, 30 groups are used for NMR testing, 30 groups for ion flow testing, and the remaining 150 groups for dry weight and ion content. In order to determine the germination index, another 1500 grains for each variety of rice seeds were selected, and divided into 30 groups, with 50 grains in each group.

Germination rate $=$ final number of germinating seeds /

total number of seeds for test $\times 100 \%$

Germination potential $=$ total number of germinating seeds on

Day 3 / total number of seeds for test $\times 100 \%$

Germination index $==\Sigma G_{t} / D_{t}$

Mean germination time $=\Sigma\left(G_{t} \times D_{t}\right) /$ total final number of

germinating seeds

where, $G_{t}$ is the number of germinating seeds on Day $t ; D_{t}$ is the corresponding number of days.

Firstly, for disinfection, all seeds were soaked with $3 \% \mathrm{NaClO}$ solution for $3 \mathrm{~min}$ to $5 \mathrm{~min}$, and then rinsed with distilled water for 3 to 5 times. After this, the seeds were placed evenly in the glass culture dish lined with filter paper. The rice seeds were divided into three treatments, namely, the treatment under the control condition, the treatment under $\mathrm{NaCl}$ stress at the $50 \mathrm{mM}$ concentration and the treatment under $\mathrm{NaCl}$ stress at $150 \mathrm{mM}$ concentration, each treatment had 10 replicates. For the control condition, appropriate amount of distilled water was added until the filter paper and the seeds were fully moistened. For the two $\mathrm{NaCl}$ stress treatment $\mathrm{s}$, equal amount of $50 \mathrm{mM}$ or $150 \mathrm{mM} \mathrm{NaCl}$ solution was added. All samples were put in the HPG-280BX illumination incubator at a constant temperature of $(27 \pm 1)^{\circ} \mathrm{C}$. Illumination was adjusted to 12-to-12 $\mathrm{h}$ alternating day-and-night mode. To keep the $\mathrm{NaCl}$ concentration stable, the solutions were replaced every $24 \mathrm{~h}$.

2.2.2 Theories and methods of moisture detection through NMR technique

Magnetic Resonance Spectroscopy (MRS) is to place the samples in a special magnetic field, and to use the radio-frequency (RF) pulses to excite the spin of the hydrogen nucleus, causing the hydrogen nucleus to resonate and to send out magnetic resonance signals of a specific frequency. The magnetic resonance signals are then converted to spectral signals through Fourier transform, which are then used as the data base for future quantitative and qualitative testing. The NMR theory shows that $T_{2}$ transverse relaxation time is closely related to the chemical environment of the proton, and directly reflects how tightly water molecules are bound to other substances. The longer the transverse relaxation $T_{2}$, the looser water molecules in the sample are bound to other substances, and the freer the proton is. Thereby, the phase and composition of water in the sample can be judged based on the starting position of the peak in $T_{2}$ relaxation inversion spectra ${ }^{[22,23]}$.

Before the moisture detection, the central frequency and hard pulse width need to be calibrated with standard oil sample. Put the standard oil sample into a $12 \mathrm{~mm}$ test tube and place the test tube in the central position of the magnet box. Then find the central frequency and the $90^{\circ}$ and $180^{\circ}$ pulse widths, using the hard pulse free induction decay (FID) sequence. Dry the surface of each group of 20 seeds with a piece absorbent tissue firstly, and put them into a $2 \mathrm{~mL}$ centrifuge tube, and then put the centrifuge tube into a glass tube. Place the glass tube in the central position of the 
permanent magnet for signal acquisition. Use the hard pulse Carr-Purcell-Meiboom-Gill sequence (CPMG) to detect the magnetic signal intensity of the sample. The mathematical formula of the relaxation signal is as follows:

$$
M(t)=\sum_{i} P_{i} \exp \left(-\frac{t}{T_{2 i}}\right)
$$

where, $M(t)$ represents the total amount of nuclear magnetic signal after time $t ; P_{i}$ stands for the signal intensity of the $i^{\text {th }}$ substance; $T_{2 i}$ represents the transverse relaxation time of the $i^{\text {th }}$ substance. Repeat the process 5 times for each group of seeds. Calculate the mean peak value of the spin echo collected by the NMR software, after removing the data of discrete value. And record this mean value as the signal value of this period. The average value will be retrieved by the inversion software T2_InvfitGeneral Ver 4.09 for inverse operation. $T_{2}$ inversion spectrum was thus created.

Parameters for CPMG sequence: frequency $S F_{l}=12 \mathrm{MHz}$; offset frequency $O_{1}=211043.01 \mathrm{~Hz} ; 90^{\circ} \mathrm{RF}$ pulse width $P_{1}=8 \mu \mathrm{s}$, $180^{\circ}$ RF pulse width $P_{2}=12 \mu \mathrm{s}$; the sampling point $T D=205032$; the number of repeated samplings $\mathrm{NS}=16$; echo number $\mathrm{NECH}=2500$; echo time $\mathrm{TE}=400 \mathrm{~ms}$.

2.2.3 Establishing the association between NMR $T_{2}$ relaxation time and moisture during seed germination

The total sum of peak area (total amplitude $A$ ) in the NMR $T_{2}$ transverse relaxation inversion spectra, is directly proportional to the number of hydrogen atoms in the sample. Different $T_{2}$ relaxation time reflects on the different phase states of water. $T_{2}$ relaxation time is divided into short relaxation time $T_{21}$ and long relaxation time $T_{22}$ according to their different phase states. The corresponding amplitude is $A_{21}$ and $A_{22}$, respectively. $T_{21}$ represents bound water, and $T_{22}$ free water. Bound water, also called conjugated water, refers to water which is tightly attracted by the hydrophilic colloid in the seeds. Bound water cannot flow freely. Bound water does not share the characteristics of typical water, and cannot be used as solvents. Free water refers to water which is not or almost not attracted by the colloid in the seeds. Free water can flow freely. Free water exists mainly in the capillary and cell clearance of the seeds. Free water shares the characteristics of typical water, and can be used as solvents. The variation of $T_{2}$ relaxation time can reflect the distribution and variation pattern of bound water and free water in the germinating rice seeds under salt stress of different concentrations. Figure 1 describes the $T_{2}$ inversion spectrum of sample YG48 at different hours of germination $(0-72 \mathrm{~h})$. The horizontal ordinate represents $T_{2}$ relaxation time. The higher the $T_{2}$ value, the looser water molecules are bound to other substances. The vertical ordinate represents the intensity of NMR signal. The stronger the signal, the more hydrogen protons there are, and the greater the moisture content. As can be seen from this figure, the first peak has a shorter relaxation time, which means that water is tightly bound up by colloid and other substances in the seeds. It bespeaks of bound water. The second peak has a longer relaxation time, which means that attraction by substances like the colloid in the seeds, is very weak. It bespeaks of free water.

2.2.4 Method for determining dry weight of rice seeds under different treatments

The rice seeds under different treatments with $0 \mathrm{~h}, 6 \mathrm{~h}, 24 \mathrm{~h}$, $48 \mathrm{~h}, 72 \mathrm{~h}$ were put into the drying box at the same time, firstly dried at $105^{\circ} \mathrm{C}$ for $30 \mathrm{~min}$, and further dried at $80^{\circ} \mathrm{C}$ to a constant weight. Each group of seeds was weighed and calculated the mean weight with an XS105DU microbalance.

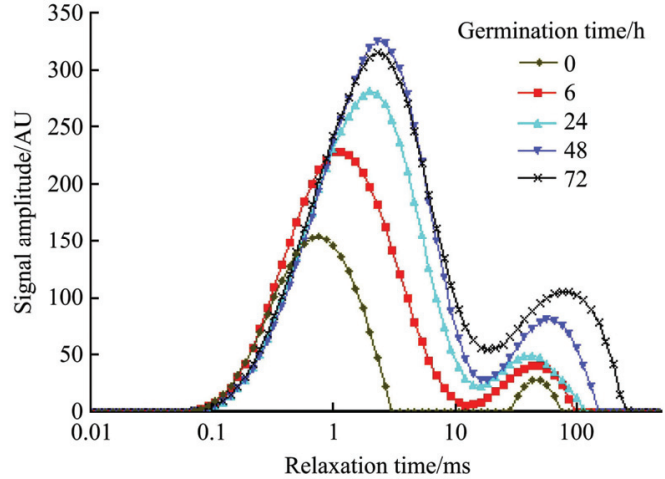

Figure $1 T_{2}$ spectrum inversion of germination rice seed within $72 \mathrm{~h}$

2.2.5 Establishment of the method for determining the moisture content of rice seeds under salt stress of different concentrations with NMR detecting technique

The total sum of peak area (total amplitude $A$ ) in the $T_{2}$ (transverse) relaxation inversion spectra is directly proportional to the number of hydrogen atoms in the sample. The hydrogen atoms are mainly from water molecules. Thus the moisture content of the rice seeds can be represented with the total sum of peak area in the relaxation spectra of NMR signals. Based on the relationship between fresh weight $f_{w}$ and dry weight $d_{w}$ of rice seeds under $\mathrm{NaCl}$ stress of different concentrations at different germinating hours, the moisture content $\mathrm{MC}(\%)$ of germinating rice seeds can be calculated. The formula is as follows:

$$
M C(\%)=\frac{f_{w}-d_{w}}{f_{w}} \times 100 \%=\frac{m_{w}}{f_{w}} \times 100 \%
$$

where, $m_{w}$ stands for the pure-water content. Thereby, through regression analysis, the regression equation between the moisture content of rice seeds and the amplitude of bound water signal $A_{21}$, the amplitude of free water signal $A_{22}$ and total amplitude $A$ in the $T_{2}$ relaxation spectra of NMR signals can be determined.

2.2.6 Theories and methods for determining $\mathrm{K}^{+}$ion flow

The scanning ion-selective electrode technique (SIET) in non-invasive micro-test technique was utilized to determine the $\mathrm{K}^{+}$ ion flow. The non-invasive micro-test system consists of 8 parts: signal acquisition, signal processing, imaging, motion control, vibration isolation table, shield, ion-selective electrode and the software (the computer). The mathematical formula of the law of ion/molecule diffusion in physics, are utilized to calculate the concentration, velocity and direction of the ion/molecule motion. The ion-selective electrode is composed of four parts: the glass microelectrode, the $\mathrm{Ag} / \mathrm{AgCl}$ conductor, the electrolyte $(100 \mathrm{mM}$ $\mathrm{KCl}$ ) and the liquid ion exchange agent (LIX). For measuring ion concentration gradient, this electrode conducted two-point testing with a known distance $d x$. The difference of concentrations between the two points $d c$ is calculated with $V_{1}, V_{2}$, the known voltage of $\mathrm{K}^{+}$microelectrode and the concentration correction curve (based on the Nernst equation) (Figure 2). $D$ is the ion/molecule specific diffusion constant, $\mathrm{pmol} /\left(\mathrm{cm}^{2} \cdot \mathrm{s}\right)$. Substitute them into the Fick's first diffusion law formula and the ion flow rate, $\mathrm{pmol} /\left(\mathrm{cm}^{2} \cdot \mathrm{sec}\right)$ will be got:

$$
J_{0}=-D \cdot d c / d x
$$

In the experiment, as shown in Figure 3, the front end of the ion-selective microelectrode is filled with $180 \mu \mathrm{m} \mathrm{K} \mathrm{K}^{+}$liquid ion exchange agent, and its back end is filled with $15-20 \mathrm{~mm}$ electrolyte. Insert the AG/AGCL conductor of the electrode retainer into the back end of the electrode till the conductor was in contact with the electrolyte. The solid electrode served as a reference electrode. The glass microelectrode needed to be 
corrected first, the correcting range being $58 \pm 3$. Glue the rice seed samples to the center of the test box filled with test fluid. Find the testing point, side distance being $100 \mu \mathrm{m}$ from the inferior palea to glume tip. Find the origin point of the testing, $50 \mu \mathrm{m}$ from the seed surface, moving range $d x=30 \mu \mathrm{m}$. Thus near- and far-point voltage $V_{1}$ and $V_{2}$ can be obtained. For each group of seeds, the above procedure was repeated in at least 10 samples. For each sample, stable measurement needed to last $10 \mathrm{~min}$.

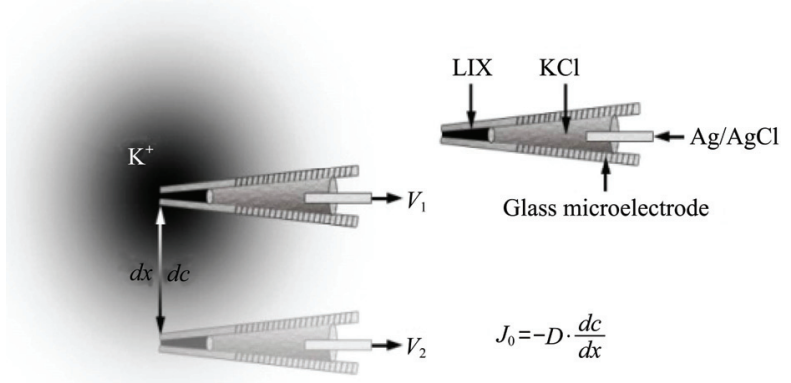

Figure 2 Theory of scanning ion-selective electrode technique

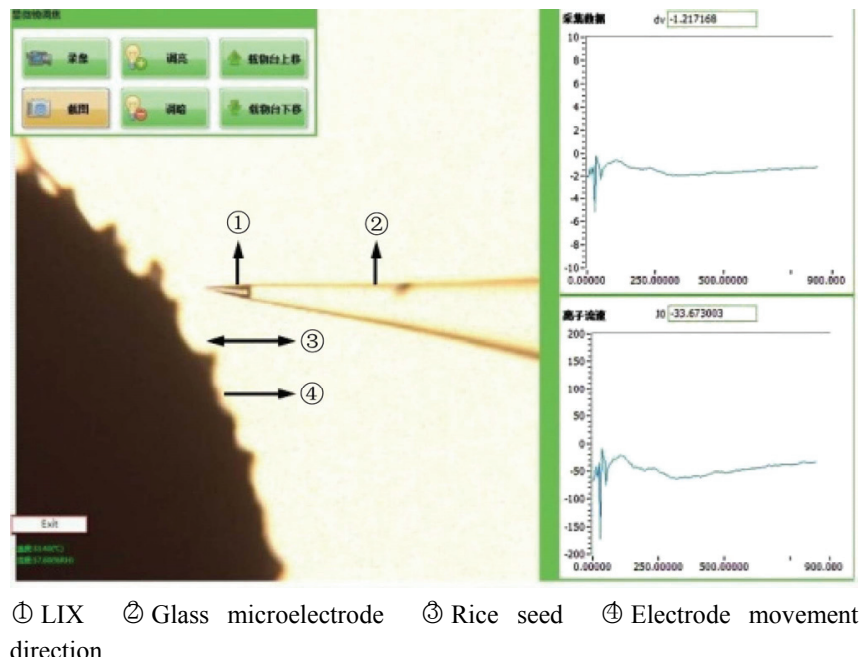

Figure 3 Sketch map of scanning ion-selective electrode technique

2.2.7 Method for determining the static ion content of $\mathrm{K}^{+}$and $\mathrm{Na}^{+}$

After crushing the dried rice seed samples with the high throughput tissue grinder TissueLyser II, measure 0.2500-0.5000 g of each sample (accurate to $0.0001 \mathrm{~g}$ ) and then they were put into the PTFE digestion tank, $5 \mathrm{~mL}$ nitric acid (of high purity) was added to the digestion tank and stood still for some time. Then the PTFE digestion tank was put into the digest equipment, and boiled at $100^{\circ} \mathrm{C}$ (up $5^{\circ} \mathrm{C} / \mathrm{min}$ ) until the sample was thoroughly digested. And then $3 \mathrm{~mL}$ hydrogen peroxide (of high purity) was added for removing the acid at $100^{\circ} \mathrm{C}$ until the concentration of the digesting liquid is lower than $2 \mathrm{~mL}$. Then they were poured into $50 \mathrm{~mL}$ plastic container bottles, and performed the constant-volume process. The content of $\mathrm{K}^{+}$and $\mathrm{Na}^{+}$were measured with the inductively coupled plasma mass spectrometer.

\subsubsection{Data analysis and processing}

In the study, one-way analysis of variance (ANVOA) was used to compare the difference of the germination index of rice seeds, the NMR signal amplitude of two water states, the $\mathrm{K}^{+}$and $\mathrm{Na}+$ content and the $\mathrm{K}^{+} / \mathrm{Na}^{+}$balance in two different rice varieties under different concentration $\mathrm{NaCl}$ solutions. Regression analysis was used to compare the relationship between the total amplitude of NMR signals and the relative moisture content of seeds. All the statistical analyses were conducted with SPSS 19.0 and the significant level is $p<0.05$.

\section{Results and analysis}

\subsection{Effects of different $\mathrm{NaCl}$ concentrations on the germination index of rice seeds}

$\mathrm{NaCl}$ stress had significant impact on the germination index and mean germination time of rice seeds $(p<0.05)$. As shown in Table 1, compared with the control condition, the mean germination time of YG48 increased by $37.6 \%$ and the germination index decreased by $25.37 \%$ when under $\mathrm{NaCl}$ stress at $50 \mathrm{mM}$. Under $\mathrm{NaCl}$ stress at $150 \mathrm{mM}$, the mean germination time increased by $48.8 \%$ and the germination index decreased by $34.25 \%$. For LX1, the mean germination time increased by $22.00 \%$ when under $\mathrm{NaCl}$ stress at $50 \mathrm{mM}$, and its germination index decreased by $21.64 \%$. When under $\mathrm{NaCl}$ stress at $150 \mathrm{mM}$, the mean germination time increased by $76.40 \%$ and its germination index decreased by $51.99 \%$.

For both of the two rice varieties, when under $\mathrm{NaCl}$ stress, the germination time grew longer and the germination index decreased. These results are consistent with the results of previous studies ${ }^{[24,25]}$ Under $\mathrm{NaCl}$ stress at $50 \mathrm{mM}$, the germination percentage of the two rice varieties remained the same, But when under $\mathrm{NaCl}$ stress at $150 \mathrm{mM}$, their germination percentage decreased significantly. This suggests that $\mathrm{NaCl}$ stress inhibits the germination of seeds, and $\mathrm{NaCl}$ stress at $150 \mathrm{mM}$ has a stronger adverse impact on seed germination. Between these two rice varieties, the decrease of the germination index and that of the germination percentage of YG48 are significantly lower than those of LX1. Accordingly, YG48 has a stronger salt-tolerant capacity than LX1.

Table 1 Changes of germination attributes of rice seed under $\mathrm{NaCl}$ stress of different concentrations

\begin{tabular}{|c|c|c|c|c|c|c|c|}
\hline $\begin{array}{c}\text { Rice } \\
\text { Varieties }\end{array}$ & $\begin{array}{l}\mathrm{NaCl} \text { concentration } \\
/ \mathrm{mM}\end{array}$ & $\begin{array}{l}\text { Germination amount } \\
\qquad / 48 \mathrm{~h}\end{array}$ & $\begin{array}{l}\text { Germination amount } \\
\qquad / 72 \mathrm{~h}\end{array}$ & $\begin{array}{l}\text { Mean germination } \\
\text { time } / \mathrm{d}\end{array}$ & $\begin{array}{l}\text { Germination } \\
\text { index }\end{array}$ & $\begin{array}{c}\text { Energy of } \\
\text { germination/\% }\end{array}$ & $\begin{array}{c}\text { Germination } \\
\text { percentage } / \%\end{array}$ \\
\hline \multirow{2}{*}{ YG48 } & 0 & $48.67 \pm 1.15 \mathrm{a}$ & $49.00 \pm 1.00 \mathrm{a}$ & $2.05 \pm 0.05 \mathrm{c}$ & $24.67 \pm 0.29 \mathrm{a}$ & $97.33 \pm 2.31 \mathrm{a}$ & $100 \mathrm{a}$ \\
\hline & 150 & $2.33 \pm 0.58 \mathrm{c}$ & $43.00 \pm 1.00 \mathrm{~b}$ & $3.05 \pm 0.05 \mathrm{a}$ & $16.22 \pm 0.49 \mathrm{c}$ & $86.00 \pm 2.00 \mathrm{~b}$ & $98.67 \pm 1.15 b$ \\
\hline \multirow{2}{*}{ LX1 } & 0 & $30.00 \pm 1.00 \mathrm{a}$ & $44.33 \pm 1.15 \mathrm{~b}$ & $2.50 \pm 0.04 \mathrm{c}$ & $20.89 \pm 0.18 \mathrm{a}$ & $90.48 \pm 2.36 \mathrm{~b}$ & $98.00 \pm 0.00 \mathrm{a}$ \\
\hline & 150 & $0 \mathrm{c}$ & $0 \mathrm{c}$ & $4.41 \pm 0.11 \mathrm{a}$ & $10.03 \pm 0.28 \mathrm{c}$ & $0 \mathrm{c}$ & $93.33 \pm 4.16 b$ \\
\hline
\end{tabular}

Note: Values are means \pm standard error, values within a column followed by different letters are significantly different at $p<0.05$.

\subsection{Effects of different $\mathrm{NaCl}$ concentrations on the NMR signal amplitude of two water states}

The germination process of seeds was closely related to the moisture content and the existing state of water within the seeds.
Water in the seeds generally exists in two different states: bound water and free water. The seeds of the two rice varieties were conducted NMR scanning at $0 \mathrm{~h}, 6 \mathrm{~h}, 24 \mathrm{~h}, 48 \mathrm{~h}, 72 \mathrm{~h}$. As shown in Table 2, as for the control condition, compared with the moisture 
content at $0 \mathrm{~h}$, the amplitude of bound water signal $A_{21}$ in YG48 increased by $98.22 \%, 153.4 \%, 181.15 \%$, and $189.45 \%$ respectively at $6 \mathrm{~h}, 24 \mathrm{~h}, 48 \mathrm{~h}$ and $72 \mathrm{~h}$; whereas the amplitude of free water signal $A_{22}$ increased by $141.48 \%, 230.11 \%, 503.23 \%$, and $960.81 \%$ respectively. And the total amplitude $A$ increased by $101.83 \%$, $159.8 \%, 208.03 \%$, and $253.82 \%$. When under $50 \mathrm{mM}$ and $150 \mathrm{mM}$ $\mathrm{NaCl}$ stress, as shown in Figure 4, the amplitude of all three signals showed a relatively small change in terms of ascending rate at $6 \mathrm{~h}$ and $24 \mathrm{~h}$, but changed significantly at $48 \mathrm{~h}$ and $72 \mathrm{~h}$. The higher the $\mathrm{NaCl}$ concentration, the sharper the decrease in the ascending rate of the amplitude. LX1 showed the same trend.

The effect of $\mathrm{NaCl}$ stress on the NMR signal amplitude of water of different phases during seed germination was significant. In this experiment, for both rice varieties, under the control condition and the stress conditions, the amplitude of the bound water signal, that of the free water signal and the total amplitude all increased as germination hours increased. The ascending trend weakened when salt concentration was higher.

Seed germination starts from imbibition, and is a complex process consisting of a series of physical and biochemical changes. Imbibition is a physical process, namely, it depends on the hydro-philicity of the protoplasm and the cell wall, but has nothing to do with the metabolism of seeds. So during the first $24 \mathrm{~h}$, for all three seed groups, the amplitude of the bound water signal $A_{21}$, that of the free water signal $A_{22}$ and the total amplitude $A$ were basically all on an increase trend. Bur after $24 \mathrm{~h}$, as seeds tended to be saturated, and the enzyme protein began to be reactivated and genes commenced to express themselves, the embryo cells started to grow and divide. At this time, the increase trend of $A_{21}, A_{22}$ and $A$ began to slow down. Under salt stress, the ascending trends of $A_{21}, A_{22}$ and $A$ were all significantly slower than those under the control condition. In addition, as $\mathrm{NaCl}$ concentration became higher, the ascending trend weakened. A possible explanation is that when under salt stress, the $\mathrm{Na}^{+}$and $\mathrm{Cl}^{-}$concentrations were higher, and as a result, the infiltration potential of the solution was increased, and water potential was decreased. That slowed down water absorption by the seeds. The higher $\mathrm{NaCl}$ concentration and the lower the water potential, the more difficult it was for seeds to absorb water.
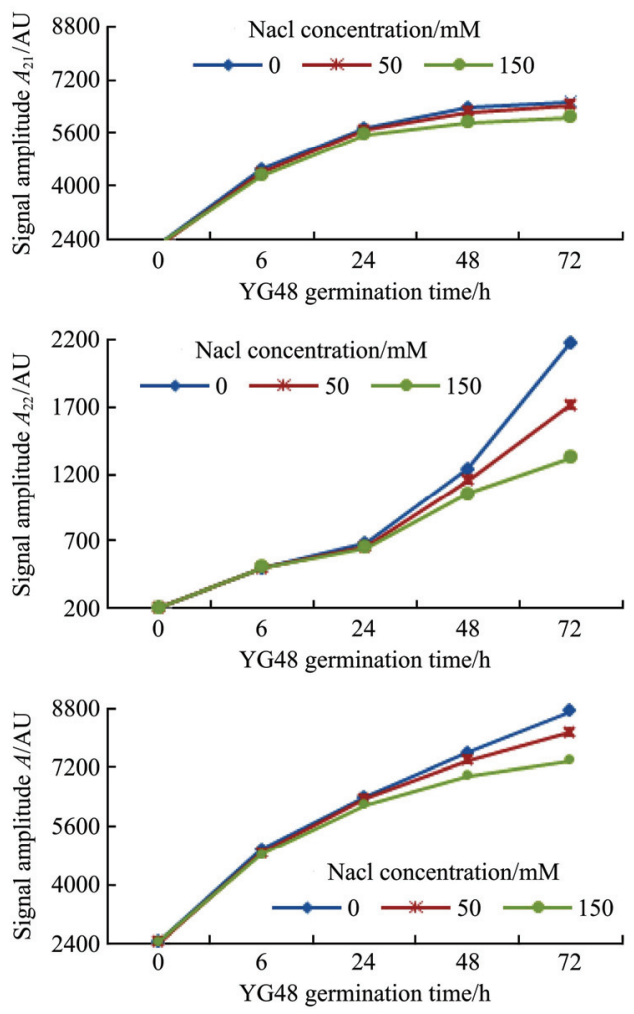

Figure 4 Changes of signal amplitude $A_{21}, A_{22}, A$ of germinating rice seed under $\mathrm{NaCl}$ stress

Table 2 NMR signal amplitude $A_{21}$ and $A_{22}$ under NaCl stress of different concentrations

\begin{tabular}{|c|c|c|c|c|c|c|c|}
\hline \multirow{2}{*}{$\begin{array}{c}\text { Rice } \\
\text { varieties }\end{array}$} & \multirow{2}{*}{$\begin{array}{l}\text { Germination } \\
\text { time } / \mathrm{h}\end{array}$} & \multicolumn{2}{|c|}{$0 \mathrm{mM} \mathrm{NaCl}$} & \multicolumn{2}{|c|}{$50 \mathrm{mM} \mathrm{NaCl}$} & \multicolumn{2}{|c|}{$150 \mathrm{mM} \mathrm{NaCl}$} \\
\hline & & $A_{21}$ & $A_{22}$ & $A_{21}$ & $A_{22}$ & $A_{21}$ & $A_{22}$ \\
\hline \multirow{4}{*}{ YG48 } & 0 & $2260.73 \pm 0.28 \mathrm{e}$ & $205.83 \pm 8.25 \mathrm{e}$ & $2233.53 \pm 43.08 \mathrm{e}$ & $205.31 \pm 7.46 \mathrm{e}$ & $2274.97 \pm 63.47 \mathrm{e}$ & $202.93 \pm 8.44 \mathrm{e}$ \\
\hline & 6 & $4481.16 \pm 37.88 \mathrm{~d}$ & $497.04 \pm 37.88 \mathrm{~d}$ & $4375.75 \pm 95.40 \mathrm{~d}$ & $495.08 \pm 31.87 \mathrm{~d}$ & $4317.84 \pm 76.21 \mathrm{~d}$ & $505.94 \pm 45.20 \mathrm{~d}$ \\
\hline & 24 & $5728.61 \pm 102.31 \mathrm{c}$ & $679.47 \pm 29.75 \mathrm{c}$ & $5699.09 \pm 73.25 \mathrm{c}$ & $659.28 \pm 46.43 \mathrm{c}$ & $5555.45 \pm 90.64 \mathrm{c}$ & $648.59 \pm 51.53 \mathrm{c}$ \\
\hline & 48 & $6356.07 \pm 132.07 \mathrm{~b}$ & $1241.63 \pm 53.30 \mathrm{~b}$ & $6243.74 \pm 73.88 \mathrm{~b}$ & $1155.93 \pm 45.82 \mathrm{~b}$ & $5922.43 \pm 73.50 \mathrm{~b}$ & $1053.18 \pm 82.43 \mathrm{~b}$ \\
\hline \multirow{5}{*}{ LX1 } & 0 & $2157.26 \pm 49.02 \mathrm{e}$ & $131.67 \pm 3.99 \mathrm{e}$ & $2129.37 \pm 53.49 \mathrm{e}$ & $140.03 \pm 7.76 \mathrm{e}$ & $2091.27 \pm 48.84 \mathrm{e}$ & $132.75 \pm 7.53 \mathrm{e}$ \\
\hline & 6 & $3997.45 \pm 86.49 \mathrm{~d}$ & $410.85 \pm 32.84 \mathrm{~d}$ & $3967.44 \pm 41.62 \mathrm{~d}$ & $429.58 \pm 38.80 \mathrm{~d}$ & $3929.36 \pm 107.63 \mathrm{~d}$ & $433.31 \pm 22.38 \mathrm{~d}$ \\
\hline & 24 & $5123.99 \pm 68.60 \mathrm{c}$ & $512.46 \pm 50.66 \mathrm{c}$ & $5068.07 \pm 130.81 \mathrm{c}$ & $523.63 \pm 32.02 \mathrm{c}$ & $5018.48 \pm 93.73 \mathrm{c}$ & $531.65 \pm 26.96 \mathrm{c}$ \\
\hline & 48 & $5914.34 \pm 80.23 \mathrm{~b}$ & $825.81 \pm 48.71 \mathrm{~b}$ & $5773.73 \pm 103.86 \mathrm{~b}$ & $810.58 \pm 46.62 b$ & $5626.18 \pm 138.19 \mathrm{~b}$ & $631.57 \pm 25.62 \mathrm{~b}$ \\
\hline & 72 & $6128.21 \pm 116.13 \mathrm{a}$ & $1460.57 \pm 94.83 \mathrm{a}$ & $6091.34 \pm 134.81 \mathrm{a}$ & $1246.63 \pm 88.16 \mathrm{a}$ & $5897.43 \pm 51.30 \mathrm{a}$ & $836.08 \pm 56.06 \mathrm{a}$ \\
\hline
\end{tabular}

Note: Values are means \pm standard error, values within a column followed by different letters are significantly different at $p<0.05$.

3.3 Effect of different $\mathrm{NaCl}$ concentrations on the ascending rate of NMR signal amplitude in the two different rice varieties

Between the two rice varieties, under $\mathrm{NaCl}$ stress at different concentrations, the ascending rates of the amplitude of bound water and free water signals at $6 \mathrm{~h}, 24 \mathrm{~h}, 48 \mathrm{~h}$, and $72 \mathrm{~h}$, were obviously different, but there was no detectible pattern. The ascending rates of total amplitude of the rice varieties also had obvious difference at $48 \mathrm{~h}$ and $72 \mathrm{~h}$. When under $50 \mathrm{mM} \mathrm{NaCl}$ stress, for YG48, the total amplitude was decreased by $3.32 \%$ at $48 \mathrm{~h}$ and $8.74 \%$ at $72 \mathrm{~h}$, whereas for LX1, the decrease percentages were $3.06 \%$ and $4.36 \%$ respectively. When under $150 \mathrm{mM} \mathrm{NaCl}$ stress, for YG48, the total amplitude decreased by $12.34 \%$ at $48 \mathrm{~h}$ and $21.27 \%$ at $72 \mathrm{~h}$, whereas for LX1, the decrease percentages were $9.38 \%$ and $14.91 \%$ respectively. As relative to the control condition, the ascending rate of the total amplitude of YG48 was less than that of LX1. This means that under salt stress, the water-absorbing capacity YG48 is less than that of LX1 at both $48 \mathrm{~h}$ and $72 \mathrm{~h}$.

3.4 Relationship between the total amplitude of NMR signals and the relative moisture content of seeds under $\mathrm{NaCl}$ stress during rice seed germination

Judging from the trends of moisture content (\%) and the total amplitude of NMR signals during seed germination, for both rice varieties under the three conditions, the moisture content and the total amplitude were obvious associated with each other. Figure 5 
shows the fitted curve of the total amplitude and the moisture content of YG48 under the three conditions. The linear regression equation is $y=191.53 x+1463.6$, the correlation coefficient is $R=0.9823$, the determinant coefficient is $R^{2}=0.9650$. The regression equation was tested with significance, $F=3528.82, p<0.05$, it reached the significant level. This indicates that there is a significant positive correlation between the data obtained through NMR technique and those obtained by the conventional dry-weight weighing method. Therefore it is a proper method to analyze the moisture change in seeds during germination based on the trend of the total amplitude of NMR signals.

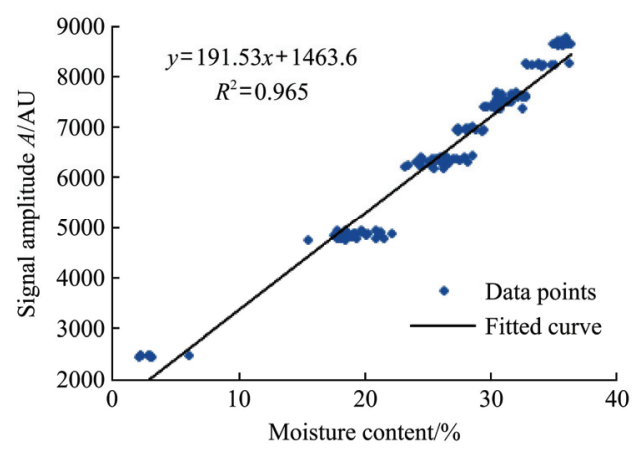

Figure 5 Fitted curve between relative moisture content and total signal amplitude

\subsection{Effects of different $\mathrm{NaCl}$ concentrations on $\mathrm{K}^{+}$ion flow in different rice varieties}

Continuous monitoring of different varieties of rice seeds under $\mathrm{NaCl}$ conditions of different concentrations with the non-invasive micro-test system showed that at $0,6 \mathrm{~h}, 24 \mathrm{~h}, 48 \mathrm{~h}$ and $72 \mathrm{~h}$ of stress, the rice seeds under the control condition absorbed $\mathrm{K}^{+}$during germination, and the velocity of $\mathrm{K}^{+}$absorption by YG48 at different hours was higher than that of LX1. Under $\mathrm{NaCl}$ stress at $50 \mathrm{mM}$ and $150 \mathrm{mM}$, the rice seeds during germination tended to remove $\mathrm{K}^{+}$. And the velocity of $\mathrm{K}^{+}$efflux in YG48 was less than that of LX1 at all different hours. These results were consistent with previous research results ${ }^{[26,27]}$. For each of the two rice varieties, at the same stress hours, the velocity of $\mathrm{K}^{+}$efflux was higher at $\mathrm{NaCl}$ concentration of $150 \mathrm{mM}$ than that at $\mathrm{NaCl}$ concentration of $50 \mathrm{mM}$. At $48 \mathrm{~h}$, there was significant difference between the two rice varieties in terms of absorbing or removing $\mathrm{K}^{+}$. The dynamic diagram of regular monitoring is shown in Figure 6. Positive value on the vertical axis means $\mathrm{K}^{+}$ efflux, whereas negative value stands for $\mathrm{K}^{+}$absorption. As can be seen from the figure, at $\mathrm{NaCl}$ concentrations of $0 \mathrm{mM}, 50 \mathrm{mM}$, and $150 \mathrm{mM}$ treatment, the velocity of $\mathrm{K}^{+}$flow for YG48 was $-102 \mathrm{pmol} /\left(\mathrm{cm}^{2} \cdot \mathrm{s}\right), 16 \mathrm{pmol} /\left(\mathrm{cm}^{2} \cdot \mathrm{s}\right)$, and $53 \mathrm{pmol} /\left(\mathrm{cm}^{2} \cdot \mathrm{s}\right)$ respectively, and that for LX1 was $-68 \mathrm{pmol} /\left(\mathrm{cm}^{2} \cdot \mathrm{s}\right), 29 \mathrm{pmol} /\left(\mathrm{cm}^{2} \cdot \mathrm{s}\right)$, and $80 \mathrm{pmol} /\left(\mathrm{cm}^{2} \cdot \mathrm{s}\right)$ respectively. There was fluctuation but overall it was stable. This reflected the real-time physiological state of rice seed germination in the two different rice varieties. The mean value of velocity of $\mathrm{K}+$ flow is shown in Figure 7.

Under normal conditions, rice seeds absorb $\mathrm{K}^{+}$. There are several possible causes for $\mathrm{K}^{+}$efflux when under $\mathrm{NaCl}$ stress. One possibility is that $\mathrm{NaCl}$ stress induced the depolarization of the cell membrane potential in rice seeds, and thus weakened the cell's power to absorb $\mathrm{K}^{+}$. Another possibility is that $\mathrm{NaCl}$ inhibited the $\mathrm{K}^{+}$channel activity between cells, and induced the opening of the outward $\mathrm{K}^{+}$channel, resulting in $\mathrm{K}^{+}$efflux. Still another possibility is that the accumulation of $\mathrm{Na}^{+}$and $\mathrm{Cl}^{-}$destroyed the cell membrane, resulting in $\mathrm{K}^{+}$efflux. After the same stress hours, the difference of efflux velocity between YG48 and LX1 were perhaps determined by the genetic characteristics of the two different rice varieties. In this experiment, the non-invasive micro-test technique was utilized to detect the $\mathrm{K}^{+}$efflux induced by salt stress. These results are in consistence with the decrease of $\mathrm{K}^{+}$content in rice seeds detected by inductively coupled plasma emission spectrometry.
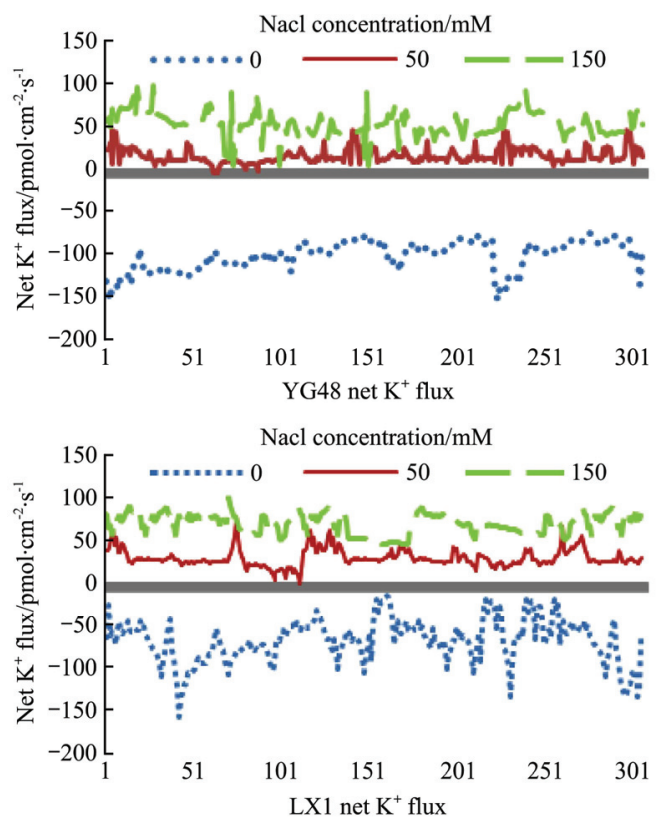

Figure $6 \mathrm{~K}^{+}$fluxes after $24 \mathrm{~h} \mathrm{NaCl}$ stress

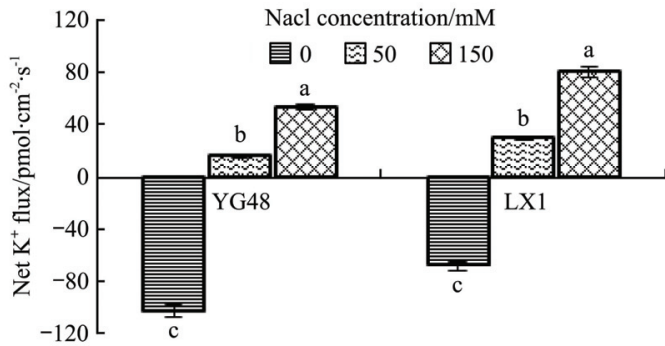

Figure 7 Mean net $\mathrm{K}^{+}$flux after $48 \mathrm{~h} \mathrm{NaCl}$ stress

3.6 Effects of different $\mathrm{NaCl}$ concentrations on the $\mathrm{K}^{+}$and $\mathrm{Na}+$ content and the $\mathrm{K}^{+} / \mathrm{Na}^{+}$balance in two different rice varieties

$\mathrm{K}^{+}$is one of the major nutrient elements of plants. One of its physiological functions is to enhance the cell's adjustment capacity when under stress. Maintaining the $\mathrm{K}^{+} / \mathrm{Na}^{+}$balance within the body is a critical means for plants to adapt to the salt-stress condition. To achieve the $\mathrm{K}^{+} / \mathrm{Na}^{+}$balance, plants try to reduce the $\mathrm{Na}^{+}$concentration in its body or cytoplasm on the one hand, by restricting the $\mathrm{s}$ entry of $\mathrm{Na}^{+}$and increasing the efflux of $\mathrm{Na}^{+}$or segmentation and endeavor to stop the loss of $\mathrm{K}^{+}$on the other hand $^{[28,29]}$.

In this experiment, under the control condition, the total accumulation of $\mathrm{Na}^{+}$in rice seeds during germination was in steady increase at 6-72 h, but the total content of $\mathrm{Na}^{+}$was relatively low, whereas the total accumulation of $\mathrm{K}^{+}$decreased continuously, but the total content of $\mathrm{K}^{+}$was relatively high. The $\mathrm{Na}^{+}$content in YG48 increased from $14.7 \mathrm{mg} / \mathrm{kg}$ to $38.7 \mathrm{mg} / \mathrm{kg}$, and its $\mathrm{K}^{+}$content decreased from $2588.7 \mathrm{mg} / \mathrm{kg}$ to $2036.7 \mathrm{mg} / \mathrm{kg}$. For LX1, however, the $\mathrm{Na}^{+}$content increased from $19.9 \mathrm{mg} / \mathrm{kg}$ to $40.7 \mathrm{mg} / \mathrm{kg}$ and the $\mathrm{K}^{+}$content decreased from $2482.5 \mathrm{mg} / \mathrm{kg}$ to $1928.7 \mathrm{mg} / \mathrm{kg}$. Between the two rice varieties, at the same germination hours, the $\mathrm{Na}^{+}$content was lower in YG48 than in $\mathrm{LX} 1$, and the $\mathrm{K}^{+}$content was higher in YG48 than in LX1. For both rice varieties, at $6 \mathrm{~h}$, 
$24 \mathrm{~h}, 48 \mathrm{~h}$ and $72 \mathrm{~h}$ of $\mathrm{NaCl}$ stress, with the increase the stress time and $\mathrm{NaCl}$ concentration, the total accumulation of $\mathrm{Na}^{+}$increased significantly, but the total accumulation of $\mathrm{K}^{+}$decreased gradually. At the same $\mathrm{NaCl}$ concentration and at the same stress hours, the $\mathrm{Na}^{+}$content was lower and the $\mathrm{K}^{+}$content was higher in YG48 than in LX1. Figures 8 and 9 compares the $\mathrm{K}^{+}$content and $\mathrm{K}^{+} / \mathrm{Na}^{+}$ balance between two rice varieties at $24 \mathrm{~h}$ of $\mathrm{NaCl}$ stress. As can be seen from the figures, the $\mathrm{K}^{+}$content and the $\mathrm{K}^{+} / \mathrm{Na}^{+}$ratio in the two rice varieties under $\mathrm{NaCl}$ stress are lower than those under the control condition. And the content of $\mathrm{K}^{+}$and the $\mathrm{K}^{+} / \mathrm{Na}^{+}$ratio under $\mathrm{NaCl}$ stress at $150 \mathrm{mM}$ concentration is lower than those at $50 \mathrm{mM}$ concentration. These results were confirmed by the efflux trend of $\mathrm{K}^{+}$when under salt stress detected by the non-invasive micro-test technique. There are two explanations for the decrease of $\mathrm{K}^{+}$accumulation. One possibility is that the ion radius and hydration energy of $\mathrm{Na}^{+}$and $\mathrm{K}^{+}$are similar to each other, and the highly active $\mathrm{Na}^{+}$competes with $\mathrm{K}^{+}$for the binding sites on the membrane, which in turn blocked the absorption of $\mathrm{K}^{+}$. Another possibility is that with the accumulation of $\mathrm{Na}^{+}$in the cell, the activity of many enzymes was destroyed, causing damage to the membrane, which in turn resulted in a substantial loss of the original $\mathrm{K}^{+}$.

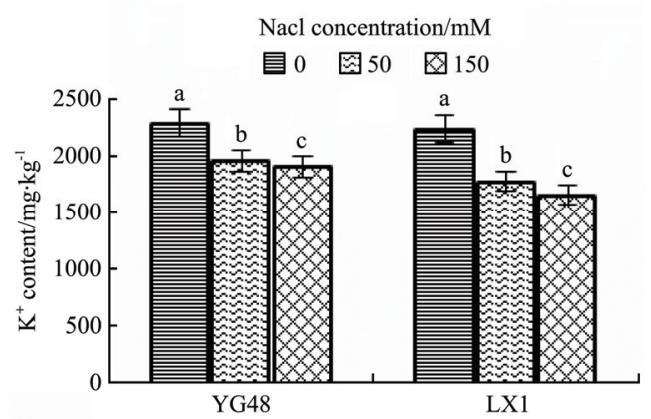

Figure 8 Mean $\mathrm{K}^{+}$iron content after $24 \mathrm{~h} \mathrm{NaCl}$ stress

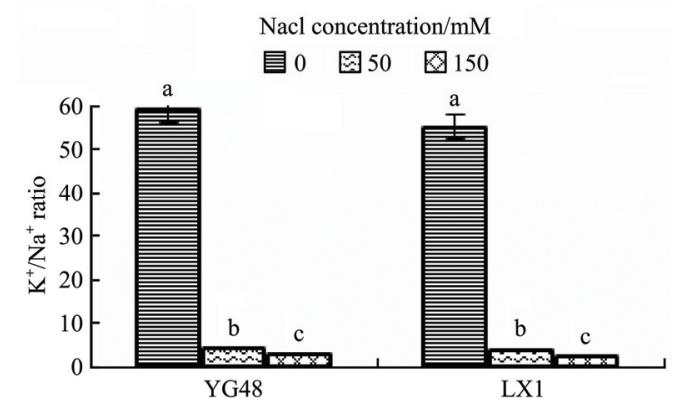

Figure $9 \mathrm{~K}^{+} / \mathrm{Na}^{+}$of iron content after $24 \mathrm{~h} \mathrm{NaCl}$ stress

\section{Discussion}

The transport of moisture across the membrane is mainly mediated by the aquaporin. The transport of ions across the membrane is mainly mediated by the ion channel. The aquaporin and $\mathrm{K}^{+}$ion channel work together during rice seed germination ${ }^{[30]}$. Salt stress is one of the major stress factors limiting rice productivity. Its adverse effect is due both to the water deficit caused by osmotic stress and to the ionic toxicity caused by ionic stress. It is very important to study the salt-tolerance of rice under salt stress, in order to improve the salt-tolerance capacity of rice and thereby increase the yield. In this experiment, water absorption and ion flux in rice seeds were studied during germination with the NMR technique and the non-invasive micro-test technique. This study found that in different rice varieties, under the control condition and $\mathrm{NaCl}$ stress condition, there is a close association between the germination indices and water absorption and ion flux.

Under $\mathrm{NaCl}$ stress, with the increase of salt concentration, the germination time increased and the germination indices decreased in both rice varieties. The germination percentage remained the same in both rice varieties under $\mathrm{NaCl}$ stress at $50 \mathrm{mM}$, but decreased significantly at $150 \mathrm{mM}$. Through NMR test, this study found that in both rice varieties, the amplitude of bound water $A_{21}$, the amplitude of free water $A_{22}$, and the total amplitude $A$ all showed an ascending trend at $0-72 \mathrm{~h}$ under the control condition, and the stress conditions of $50 \mathrm{mM}$ and $150 \mathrm{mM} \mathrm{NaCl}$. The higher the $\mathrm{NaCl}$ concentration, the sharper the decrease in the ascending rate of the amplitude. This was in consistent with the descending trend of germinating indices of both two rice varieties under salt stress. But further studies need to be conducted as to which phase of water is more closely associated with the germination indices, bound water or free water. From the analysis of germination indices, this study found that the salt tolerance of YG48 is stronger than LX1. But the water absorption in YG48 relative to the control condition is less than that in LX1. Therefore, we caution against judging the salt tolerance of rice variety solely by water absorption capacity.

In both rice varieties, continuous monitoring of $\mathrm{K}^{+}$with the non-invasive micro-test technique revealed that the rice seeds under the control condition absorbed $\mathrm{K}^{+}$all through the germination hours, but when under $\mathrm{NaCl}$ stress, $\mathrm{K}^{+}$efflux tend to happen. And both the $\mathrm{K}^{+}$content and the $\mathrm{K}^{+} / \mathrm{Na}^{+}$ratio when under $\mathrm{NaCl}$ stress are lower than when under control condition. The higher the $\mathrm{NaCl}$ concentration, the lower the $\mathrm{K}^{+}$content and the $\mathrm{K}^{+} / \mathrm{Na}^{+}$ratio. This is consistent with the descending rate of germination indices under salt stress in both rice varieties. Therefore, there is positive correlation between the salt tolerance of rice seeds and the $\mathrm{K}^{+}$ content and the $\mathrm{K}^{+} / \mathrm{Na}^{+}$ratio in the seeds.

$\mathrm{NaCl}$ stress not only causes osmotic stress to rice seed cells, but also the excessive accumulation of $\mathrm{Na}^{+}$and $\mathrm{Cl}^{-}$in the cells is toxic. Further study is needed to determine how the osmotic stress and ionic toxicity that result in the decrease of germination index of different rice varieties.

\section{Conclusions}

(1) Based on the theory of NMR and multicomponent characteristic of $T_{2}$ relaxation spectra, when inversion frequency was 10000 times, the water in rice seeds during germination was categorized into two phases, and defines that short relaxation time stands for bound water and long relaxation time stands for free water. Both under control condition and stress conditions, the amplitude of bound water signals, that of free water signals and the total amplitude are all on a gradual ascending trend. The higher the $\mathrm{NaCl}$ concentration is, the slower the ascending trend. The change in the amplitude of NMR signals directly reflects the moisture distribution and absorption of rice seeds during germination.

(2) At $0-72 \mathrm{~h}$ during the germination process, under control condition and the $\mathrm{NaCl}$ stress conditions at $50 \mathrm{mM}$ and $150 \mathrm{mM}$, the water absorption and the total amplitude of NMR signals were on a gradual ascending trend, but $\mathrm{NaCl}$ inhibited the ascending rate of both. The higher of $\mathrm{NaCl}$ concentration is, the higher the inhibiting effect is. The moisture content of the seeds and the total amplitude of NMR signals were positively correlated. The correlation coefficient is $R=0.9823$, and the coefficient of determination is $R^{2}=0.9650$. Significance testing of the regression 
equation showed that it reached the extremely significant level. This indicates that the data obtained through NMR technique were in consistent with those obtained by the conventional dry-weight weighing method. Therefore, it is a proper method to detect the moisture content in seeds during germination with NMR technique.

(3) The absorption or efflux trends of $\mathrm{K}^{+}$under $\mathrm{NaCl}$ stress detected by the scanning ion-selective electrode technique (SIET) in the non-invasive micro-test are consistent with the contents of $\mathrm{K}^{+}$and $\mathrm{Na}^{+}$obtained by the inductively coupled plasma emission spectrometry (ICP-AES). Information on the flow rate and flow direction of ion/molecule obtained by non-invasive micro-test technique, not only reflected the dynamic process of biological physiology, but also was the relatively comprehensive information. This indicates that the information on the ion/molecule flow obtained by the non-invasive micro-test technique is a very comprehensive and direct reflection of the biological function and physiological mechanism. The combination of the non-invasive micro-test technique and NMR technique will provide a new biopsy microscopic non-invasive testing method for plants under stress.

\section{Acknowledgments}

This study was supported by National Natural Science Fund of China (Grant No. 31701318, 31601216), National Key Research and Development Program (Grant No. 2017YFD0701205) and Science and Technology Innovation Capacity Building Project of Beijing Academy of Agricultural and Forestry Science (Grant No. KJCX20170418).

\section{[References]}

[1] Demidchik V, Tester M. Sodium fluxes through nonselective cation channels in the plasma membrane of protoplasts from Arabidopsis roots. Plant Physiology, 2002; 128(2): 379-387.

[2] Zhang J L, Flowers T J, Wang S M. Mechanisms of sodium uptake by roots of higher plants. Plant \& Soil, 2010; 326(1-2): 45-60.

[3] Akter L, Fakir O A, Alam M K, Ul Islam M, Chakraborti P, Alam M J, et al. Amelioration of salinity stress in maize seed germination and seedling growth attributes through seed priming. Open Journal of Soil Science, 2018; 8: 137-146.

[4] Pinheiro C L, Araújo H T N, De Brito S F, Maia M S, Viana J S, Filho S M. Seed priming and tolerance to salt and water stress in divergent grain sorghum genotypes. American Journal of Plant Sciences, 2018; 9: 606-616.

[5] Koffler B E, Luschin-Ebengreuth N, Zechmann B. Compartment specific changes of the antioxidative status in Arabidopsis thaliana during salt stress. Journal of Plant Biology, 2015; 58(1): 8-16.

[6] Bu Y, Kou J, Sun B, Takano T, Liu S K. Adverse effect of urease on salt stress during seed germination in Arabidopsis thaliana. Febs Letters, 2015; 589(12): 1308-1313.

[7] Maswada H F, Djanaguiraman M, Prasad P V V. Seed treatment with nano-iron (III) oxide enhances germination, seedling growth and salinity tolerance of sorghum. Journal of Agronomy and Crop Science, 2018; 204: 577-587.

[8] Peng Y L, Bao J, Ye L S, Wang Y J, Yan L B. Ion homeostasis in germinating seeds and seedlings of three maize inbred lines under salt stress. Acta Ecologica Sinica, 2014; 34(24): 7320-7328. (in Chinese)

[9] Ma R, Wang C, Ma Q, Hou P C, Wang X D. Ion response of sunflower at sprouting stage to mixed salt stress. Chinese Journal of Eco-Agriculture, 2017; 25(5): 720-729. (in Chinese)

[10] Song P, Song P, Yang H W, Yang T, Xu J, Wang K T. Detection of rice seed vigor by low-field nuclear magnetic resonance. Int $\mathrm{J}$ Agric \& Biol Eng, 2018; 11(6): 195-200.

[11] Song P, Xu J, Ma H N, Wang C, Yang T, Gao H. Moisture phase state and distribution characteristics of seed during rice seed soaking process by low field nuclear magnetic resonance. Transactions of the CSAE, 2016;
32(6): 204-210. (in Chinese)

[12] Yang H W, Zhang L Y, Ji J W, Wang C, Wang X D, Song P, et al. Analysis on water absorption of rice seeds during germination process under polyethylene glycol solution using low-field nuclear magnetic resonance. Transactions of the CSAE, 2018; 34(17): 276-283. (in Chinese)

[13] Duan W J, Li Y, Cui L, Liu F, Yang G H, Guo L P, et al. Analyze moisture transformation and transport rules during processing of paeoniae radix alba by using low-field NMR. China Journal of Chinese Materia Medica, 2017; 42(11): 2092-2096. (in Chinese)

[14] Guo G F, Li B, Liu C X, Jin X, Wang Z G, Ding M Z, et al. Characterization of moisture mobility and diffusion in fresh tobacco leaves during drying by the TG-NMR analysis. Journal of Thermal Analysis \& Calorimetry, 2019; 135(4): 2419-2427.

[15] Hamza S M, Rizk N M H, Matter H A B. A new ion selective electrode method for determination of oseltamivir phosphate (Tamiflu) and its pharmaceutical applications. Arabian Journal of Chemistry, 2012; 10: S236-S243.

[16] D'Silva N M, Donini A, O'Donnell M J. The roles of V-type $\mathrm{H}^{+}$-ATPase and $\mathrm{Na}^{+} / \mathrm{K}^{+}$-ATPase in energizing $\mathrm{K}^{+}$and $\mathrm{H}^{+}$transport in larval Drosophila gut epithelia. Journal of Insect Physiology, 2017; 98: 284-290.

[17] Bojórquez-Quintal E, Velarde-Buendía A, Ku-González A, Carillo-Pech M, Ortega-Camacho D, Echevarría-Machado I, et al. Mechanisms of salt tolerance in habanero pepper plants (Capsicum chinense Jacq.): Proline accumulation, ions dynamics and sodium root-shoot partition and compartmentation. Frontiers in Plant Science, 2014; 5(3): 605-618.

[18] Yasmine F B, Eman S E, Hebat A M E, Hala E Z. Ion selective electrode approach for in-line determination of benzydamine hydrochloride in different matrices of pharmaceutical industry. Anal Bioanal Electrochem, 2017; 9(1): 65-79.

[19] Zhang H L , Zhang Y N , Deng C , Deng S R, Li N F, Zhao C J, et al. The arabidopsis $\mathrm{Ca}^{2+}$-dependent protein kinase CPK12 is involved in plant response to salt stress. International Journal of Molecular Sciences, 2018; 19(12): 4062.

[20] Chakraborty K, Bose J, Shabala L, Shabala S. Difference in root $\mathrm{K}^{+}$ retention ability and reduced sensitivity of $\mathrm{K}^{+}$-permeable channels to reactive oxygen species confer differential salt tolerance in three Brassica species. Journal of Experimental Botany, 2016; 67(15): 4611-4625.

[21] Wang Q H, Zhang T, Ma M H. Oxygen breathing regularity of eggs in storage period monitoring by non-invasive micro-test technique. Transactions of the CSAE, 2014; 30(5): 255-261. (in Chinese)

[22] Lv W Q, Adlikari B, Zhang M, Wang Y C. Online measurement of moisture content, moisture distribution, and state of water in corn kernels during microwave vacuum drying using novel smart NMR/MRI detection system. Drying Technology, 2018; 36(13): 1592-1602.

[23] Wei S, Tian B Q, He F, Jia H F, Zhang H Y, Song Z P. Investigation on water distribution and state in tobacco leaves with stalks during curing by LF-NMR and MRI. Drying Technology, 2018; 36(12): 1515-1522.

[24] Santo A, Mattana E, Frigau L, Marzo P, Picher M M, Bacchetta G. Effects of $\mathrm{NaCl}$ stress on seed germination and seedling development of brassica insularis moris (brassicaceae). Plant Biology, 2017; 19(3): 368-376.

[25] Wang Q L, Yan F, Hou L Y, Zhang W B, Hua J. Effect of $\mathrm{NaCl}$ stress on seed germination and salt-tolerance evaluation among different inbred lines of pepper. Northern Horticulture, 2018; 4: 1-8. (in Chinese)

[26] Zhu Z M , Mao G L , Xu X, Wang S, Zheng R, Yang S J. Effect of salt stress and inhibitor on uptake and transportation of $\mathrm{Na}+$ and $\mathrm{K}^{+}$in the root of Ningxia Lycium barbarum L. Agricultural Research in the Arid Areas, 2017; 35(6): 140-145. (in Chinese)

[27] Tang X Q, Li H Y, Yang X Y, Liu Z X, Zhang H X. Effects of short-time salt stress on distribution and balance of $\mathrm{Na}^{+}$and $\mathrm{K}^{+}$in nitraria sibirica pall seedlings. Forest Research, 2017; 30(6): 1022-1027. (in Chinese)

[28] Percey W J, Shabala L, Breadmore M C, Gurjt R M, Bose J, Shabala S. Ion transport in broad bean leaf mesophyll under saline conditions. Planta, 2014; 240(4): 729-743.

[29] Feki K, Quintero F J, Khoudi H K, Leidi E O, Masmoudi K, Pardo J M, et al. A constitutively active form of a durum wheat $\mathrm{Na} / \mathrm{H}$ antiporter $\mathrm{SOS}_{1}$ confers high salt tolerance to transgenic Arabidopsis. Plant Cell Reports, 2014; 33(2): 277-288.

[30] Liu H Y, Sun W N, Su W A, Tang Z C. Co-regulation of water channels and potassium channels in rice. Physiologia Plantarum, 2006; 128(1): 58-69. 